\title{
The Bushveld LIP after 100 years; a petrogenetic update and quo vadis
}

\author{
HANNAH HUGHES ${ }^{1 *}$, CHRIS HAWKESWORTH ${ }^{2}$, JUDITH \\ KINNAIRD $^{3}$, IAIN MCDONALD ${ }^{4}$, GRANT BYBEE ${ }^{3}$, \\ LAURENCE ROBB 3 \\ ${ }^{1}$ Camborne School of Mines, University of Exeter, Penryn, \\ Cornwall, UK; *email: h.hughes@exeter.ac.uk \\ ${ }^{2}$ School of Earth Sciences, University of Bristol, UK \\ ${ }^{3}$ School of Geoscience, University of the Witwatersrand, \\ Johannesburg, South Africa
}

${ }^{4}$ School of Earth and Ocean Sciences, Cardiff University, UK

${ }^{5}$ Department of Earth Sciences, University of Oxford, UK

The Palaeoproterozoic Large Igneous Province (LIP) of the Bushveld of southern Africa is one of the largest continental magmatic events on Earth, made famous by its immense mineral wealth, notably in platinum-group elements (PGE) and chromium (Cr). Yet the processes leading to the formation of the Bushveld remain an enduring topic of debate, partly underpining ideas fundamental to global 'metallogenesis'. In particular, distinctive features of the layered mafic rocks of the Bushveld (Rustenburg Layered Suite, RLS) include its apparent lithospheric signature and elevated halogen content; the marked changes in $\mathrm{Sr}$ isotope ratio throughtout its stratigraphy, indicating open behaviour of the magmatic system and the evident role that this played in mineralisation; and the PGE concentrations of parental magmas and shifts in $\mathrm{Pt} / \mathrm{Pd}$ ratio. Further, the LIP-wide association of (ultra)mafic to felsic and alkaline lithologies highlights a plethora of sources and fractionating mechanisms in operation during its formation. Following a century of research, fundamental questions remain about the magmas that formed the Bushveld LIP and the metals within it: (i) What were the magma and metal source(s)? (ii) What was the tectonic and geodynamic setting into which the Bushveld LIP was emplaced? (iii) How could such a vast LIP form within a few million years? and (iv) is the Bushveld unique, representative of an exclusive combination of factors?

In this paper, we integrate evidence spanning the tectonic and geodynamic regime in place during magmatism of the Bushveld LIP, the composition of its parental magmas in context with evidence from mantle xenoliths, and the relationships between its intrusive and extrusive components. We discuss the spatial and temporal scale of the Bushveld and the efficiency with which mineralisation processes were required to operate in order to form the metal wealth of the province. Ultimately we seek to shed light on just what is so special about the Bushveld LIP. 